\title{
Domestic Violence against Men
}

\author{
Jyoti Srivastava \\ College of Nursing, Institute of Medical Sciences, BHU, Varanasi
}

\begin{abstract}
Male and Female, the two basic components of our human society, depend upon each other and each one of them constitutes about half of the population. So we find that man and woman have been established as the two wheels of a chariot. The aim of the study was to assess the domestic violence against men. This was a descriptive study of 30 married men living in urban area of Varanasi. The result of the study showed that, majority of men had mild and moderate domestic violence. The most prominent causes of domestic violence in men were dominant behaviour and attention seeking behaviour of wife. So there is a need to counselling of couple before and after marriage.
\end{abstract}

Keywords: Men, Domestic violence, Assessment, Intimate partner violence, Marriage.

\section{Introduction}

Domestic violence against men deals with domestic violence experienced by men or boys in an intimate relationship such as marriage, cohabitation, dating, or within a family. Male victims of intimate partner violence have become a serious issue in the United States.

According to Menard (2009), approximately 3.8 women and 1.3 men per 1,000 are victims of intimate partner violence each year. The Bureau of Justice Statistics (2007) noted that each year approximately 1,181 women and 329 men are victims of intimate partner homicides. Even though the numbers are not as high for men as for women, these victims cannot be ignored.

Domestic violence is more dangers than cancer, motor vehicle accidents, war and malaria. It cuts across boundaries of age, race, culture, wealth and geography (Kaur, 2011). No country or community is untouched by violence. Each year, more than 1.6 million people worldwide lose their lives to violence. For every one who dies as a result of violence, many more are injured and suffer from a range of physical, sexual, reproductive and mental health problems (Linda and Etienne, 2002).

According to Lowenstein (2005), the past patriarchal society has led to the inequality of women's points of view about social problems such as domestic violence. Earlier, police departments viewed these disturbances as family squabbles and not as violence against an individual. Therefore, these disturbances were not treated with the same seriousness as an assault on a total stranger.

The victimization of men by their women partners is a serious social problem and it is largely ignored by the society. A part of America's social norm reveals that men are the stronger and more dominating gender who does not allow women to dominate. Consequently, male victims do not freely admit being victims of intimate partner violence at the hands of females (Barber, 2008).

The social power structure of America is argued to be supporting the culture of male domination. According to Hines, Brown, and Dunning (2007), "this societal power structure is reflected in interpersonal relationships, and men misuse the power they have in their relationships because they have been socialized to believe they have the right to control women, even though violent means,". This philosophy of thought has led to the difficulty of believing whether females were even capable of being perpetrators of intimate partner violence and whether females were acting in self-defence from their attackers (Hines, Brown, \& Dunning, 2007).

Victims of domestic violence are often married men. Incidence of home based violence against men is high though it is unreported. Violence is unacceptable and no men deserve to be beaten, sexually abused or made to suffer emotionally. Our society has created an environment, where the society is tolerant of the abuser and is intolerant of the victim. However, domestic violence is a sensitive issue and therefore very little information is available. This study will try to determine and fulfill the gap leading to violence against men.

Generally speaking, domestic violence is regarded as family business, which does not require intervention of law. Hence many cases remain unreported and it will continues to remain behind closed doors as long as the society continues to regard domestic violence as normal, or to dismiss it as a private matter. Then men or women continue to suffer gross violations of human right within their homes.

The women assault against men due to many reasons such that to resolve the arguments, to respond to family crisis, to stop him bothering me, etc. So in this way there is a need for the study to confirm women as the perpetrator $\&$ the men as the victim.

\section{Objectives of the Study}

- To assess the magnitude and pattern of domestic violence in men.

- To identify the causes of domestic violence in men.

\section{Methodology}

\section{Research Approach}

The descriptive research is the utilization of accurate description of characteristic of individual situation. 


\section{International Journal of Science and Research (IJSR) \\ ISSN (Online): 2319-7064}

Index Copernicus Value (2013): 6.14 | Impact Factor (2014): 5.611

\section{Research Design}

A non-experimental research design was used.

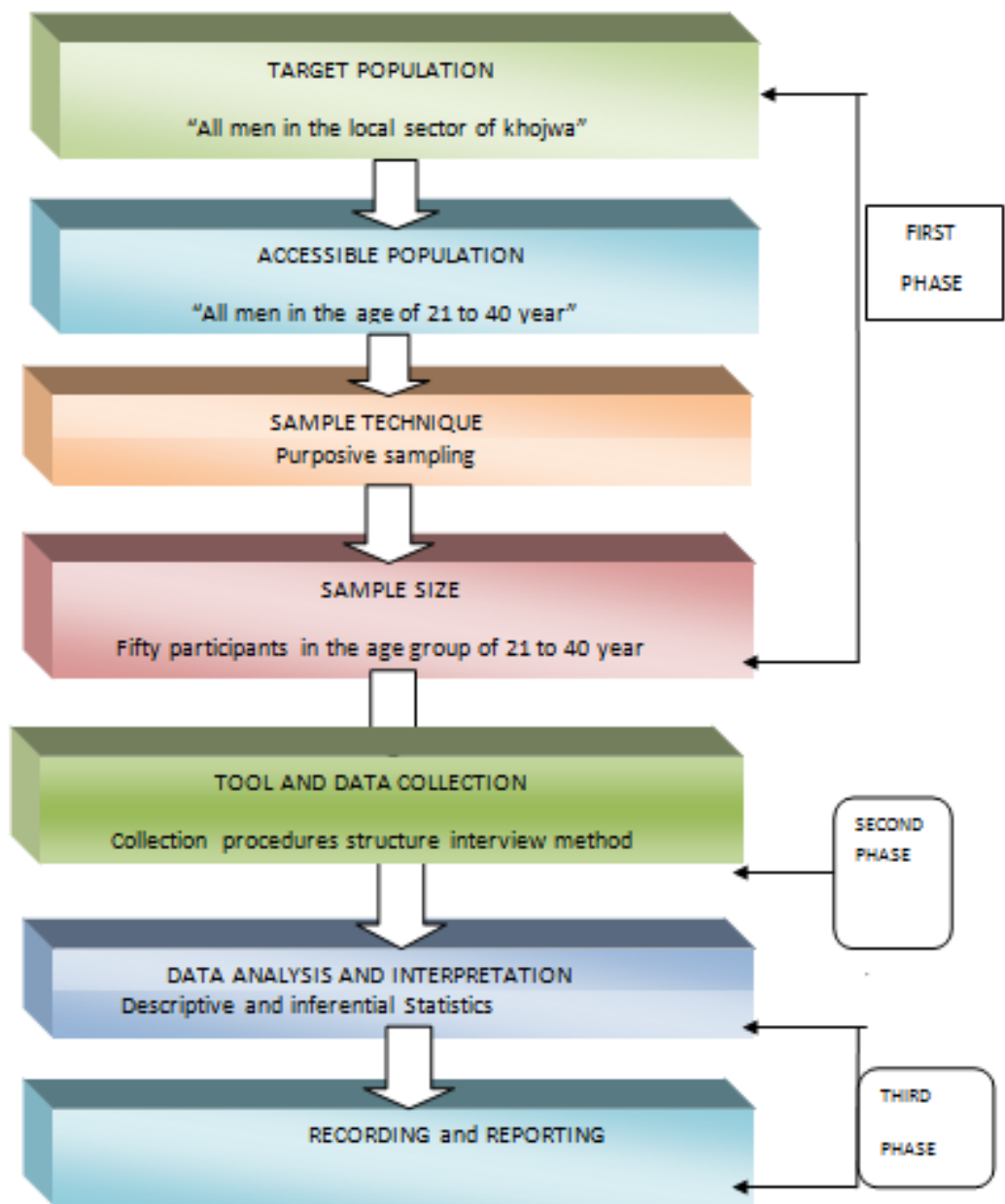

Figure 1: Schematic Representation of Research Design

\section{Setting of the Study}

This study was conducted in the locality khojwa, it is the urban locality and population approximately 2000-5000

\section{Population}

The population consist of men in the age group of 21 to 40 years from the locality khojwa.

\section{Sample Technique}

A purposive sampling technique was used to select the sample for the study on the basis of inclusive criteria.

\section{Sample Size}

In this study the sampling compromise of 50 men in the age group of 21 to 40 years.

\section{Sample Selection Criteria}

\section{Inclusion criteria}

Age between 21 to 40 years, who are ready to participate in the study.

Available at the time of data collection.

Understand and respond in Hindi.

\section{Development and Description of the Tool}

Structure interview schedule was used to assess domestic violence. The tool was prepared on the basis of the objective of the study. The tools used in the study are: Demographic variables and questionnaire was developed to measure the attitude, values and feelings of men. It was five-point scale (strongly agree, agree, uncertain, disagree and strongly disagree). Written permission was obtained from the concerned authority before data collection and confidentiality of their responses and consent was obtained from each participant.

\section{Observation and Results}




\section{International Journal of Science and Research (IJSR) \\ ISSN (Online): 2319-7064}

Index Copernicus Value (2013): 6.14 | Impact Factor (2014): 5.611

Table 1: (a) frequency and percentage of distribution of sample according to demographic variables

\begin{tabular}{|c|c|c|c|}
\hline \multirow{2}{*}{\multicolumn{2}{|c|}{ Variable }} & \multicolumn{2}{|c|}{ MALE $(\mathrm{N}=30)$} \\
\hline & & Frequency (n) & Percentage (\%) \\
\hline \multicolumn{4}{|l|}{ Age } \\
\hline 1) & $21-25$ & 04 & 13.3 \\
\hline 2) & $26-30$ & 06 & 20.0 \\
\hline 3) & $31-35$ & 08 & 26.7 \\
\hline 4) & $36-40$ & 12 & 40.0 \\
\hline \multicolumn{4}{|c|}{ Religion } \\
\hline 1) & Hindu & 26 & 86.7 \\
\hline 2) & Muslim & 02 & 06.7 \\
\hline 3) & Sikh & 01 & 03.3 \\
\hline 4) & Christian & 01 & 03.3 \\
\hline \multicolumn{4}{|c|}{ Qualification of husband } \\
\hline 1) & Illiterate & 01 & 03.3 \\
\hline 2) & Primary school & 00 & 00.0 \\
\hline 3) & High school & 02 & 06.7 \\
\hline 4) & Intermediate & 02 & 06.7 \\
\hline 5) & Graduate & 09 & 30.0 \\
\hline 6) & Post graduate & 14 & 46.7 \\
\hline 7) & Ph.D. & 02 & 06.7 \\
\hline \multicolumn{4}{|c|}{ Qualification of wife } \\
\hline 1) & Illiterate & 03 & 10.0 \\
\hline 2) & Primary school & 01 & 03.3 \\
\hline 3) & High school & 06 & 20.0 \\
\hline 4) & Intermediate & 04 & 13.3 \\
\hline 5) & Graduate & 12 & 40.0 \\
\hline 6$)$ & Post graduate & 03 & 10.0 \\
\hline 7) & Ph.D. & 01 & 03.3 \\
\hline \multicolumn{4}{|c|}{ Occupation of husband } \\
\hline 1) & Unemployed & 05 & 16.7 \\
\hline 2) & Farmer & 03 & 10.0 \\
\hline 3) & Business & 02 & 06.7 \\
\hline 4) & Private job & 08 & 26.7 \\
\hline 5) & Govt. job & 12 & 40.0 \\
\hline \multicolumn{4}{|c|}{ Occupation of wife } \\
\hline 1) & House wife & 20 & 66.7 \\
\hline 2) & Private job & 04 & 13.3 \\
\hline 3) & Govt. job & 06 & 20.0 \\
\hline
\end{tabular}

Table no.1, Majority of the subjects $12(40 \%)$ were in the age group of 36-40 years, 26(86.7\%) were Hindu and 2(0.67\%) Muslim, qualification of men, $14(46.7 \%)$ were up to postgraduate, $9(30 \%)$ graduate, $2(6.7 \%)$ high school, intermediate and Ph.D., 1(3.3\%) were illiterate. The Majority of occupation of men, 12(40\%) were working in government job, $8(26.7 \%)$ in private job, qualification of women $12(40 \%)$ up to graduation, $6(20 \%)$ of high school, and $20(66.7 \%)$ occupation of women were housewife.

Table 1: (b) frequency and percentage of distribution of sample according to demographic variables

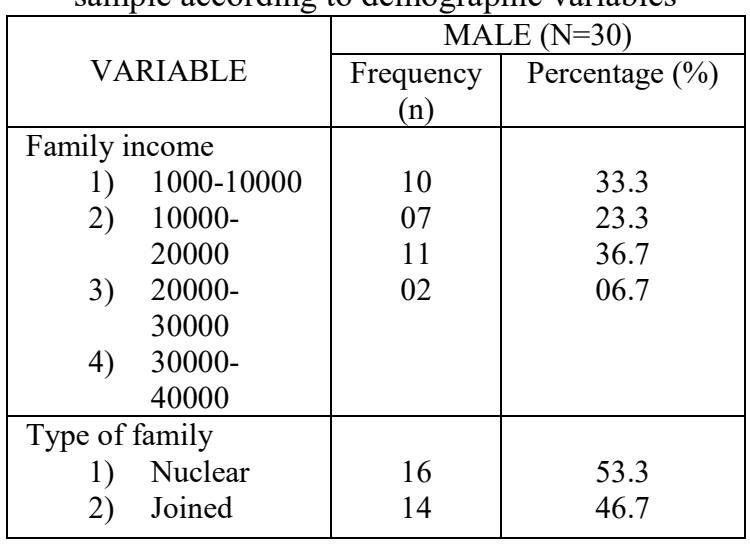

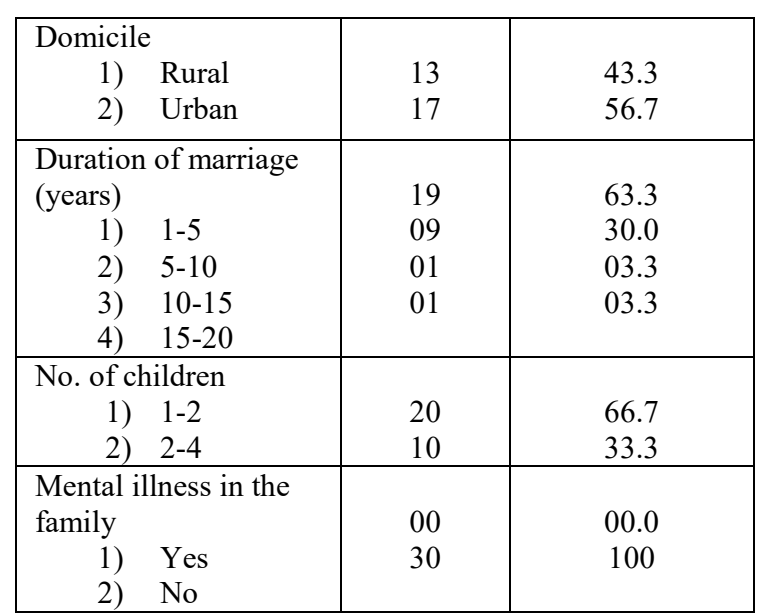

Table 1(b), 11(36.7\%) of the subjects had family income Rs 20,000-30,000 per month. The vast majority of subjects hailed from nuclear families $16(53.3 \%)$ and followed by $14(46.7 \%)$ joined family. About $1 / 2$ of the subjects had urban domicile $17(56.7 \%)$ the remaining subjects $13(43.3 \%)$ resided in rural areas. Majority $19(63.3 \%)$ of duration of marriage of men were 1-5 years. $20(66.7 \%)$ men has $1-2$ children. There was no mental illness in the family.

Table 2: Domestic violence in men

\begin{tabular}{|c|c|c|}
\hline Domestic violence & Frequency & Percentage \\
\hline Present & 11 & $36.7 \%$ \\
\hline Absent & 19 & $63.3 \%$ \\
\hline
\end{tabular}

Table No. 2, showed that 11(36.7\%) domestic violence present in men and 19(63.3\%) Domestic violence absent in men.

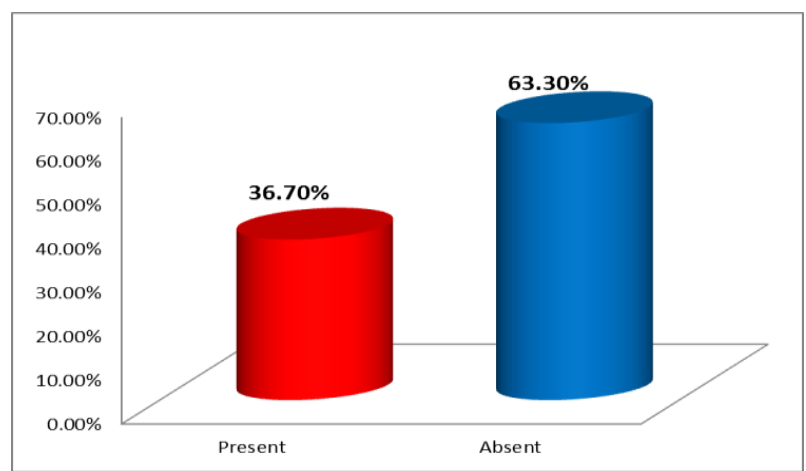

Figure 2: Domestic violence in men

Table 3: Severity of Domestic violence $\mathrm{N}=30$

\begin{tabular}{|c|c|c|}
\hline Domestic violence & Frequency & Percentage \\
\hline Mild & 07 & $23.3 \%$ \\
\hline Moderate & 04 & $13.3 \%$ \\
\hline Severe & 00 & $00.0 \%$ \\
\hline
\end{tabular}

Table no 3, showed that $07(23.3 \%)$ mild domestic violence, $04(13.3 \%)$ moderate domestic violence and there was no severe domestic violence present in men.

Table 4: Prevalence of domestic violence $\mathrm{N}=30$

\begin{tabular}{|c|c|c|}
\hline Domestic Violence & Frequency & Percentage \\
\hline Emotional & 11 & $36.7 \%$ \\
\hline Economical & 09 & $30.0 \%$ \\
\hline Sexual & 06 & $20.0 \%$ \\
\hline Physical & 00 & $00.0 \%$ \\
\hline
\end{tabular}




\section{International Journal of Science and Research (IJSR) \\ ISSN (Online): 2319-7064 \\ Index Copernicus Value (2013): 6.14 | Impact Factor (2014): 5.611}

Table 4 showed that emotional domestic violence $11(36.7 \%)$, economical domestic violence 09(30\%), and sexual domestic violence $06(20 \%)$ present in men.

Table 5: Causes of domestic violence in men $\mathrm{N}=11$

\begin{tabular}{|l|c|c|c|}
\hline & Causes & Frequency & Percentage \\
\hline $\mathbf{1}$ & Dominant behaviour of wife & 9 & 81.8 \\
\hline $\mathbf{2}$ & Attention seeking behaviour & 8 & 72.7 \\
\hline $\mathbf{3}$ & Always right attitude & 8 & 72.7 \\
\hline $\mathbf{4}$ & Self-defence behaviour & 6 & 54.5 \\
\hline $\mathbf{7}$ & Complain about Physical illness & 5 & 45.5 \\
\hline $\mathbf{8}$ & Suspicious behaviour & 4 & 36.4 \\
\hline $\mathbf{9}$ & Not fulfilment of sexual need by & 4 & 36.4 \\
& the husband & & \\
\hline $\mathbf{1 0}$ & Higher incomes than men & 3 & 27.3 \\
\hline $\mathbf{1 2}$ & Husband Unemployed & 3 & 27.3 \\
\hline $\mathbf{1 3}$ & Economic problems (Poverty) & 3 & 27.3 \\
\hline
\end{tabular}

Table No 5: show that causes of domestic violence in men 9 $(81.8 \%)$ were in dominant behaviour of wife. $8(72.7 \%)$ Attention seeking behaviour of wife, $8(72.7 \%)$ always right attitudes of wife, $6(54.5 \%)$ Self-defence behaviour, $5(45.5 \%)$ Complain about physical illness, 4(36.4\%) suspicious behaviour found in female, 4(36.4\%) not fulfilment of sexual need by the husband, 3(27.3\%) Female have higher income than men, 3(27.3\%) husband unemployed, 3(27.3\%) economic problems (poverty) and $3(27.3 \%)$ husband not good looking are presented.

\section{Discussion}

The present inquiry was a modest attempt to study the frequency, severity and causes of Domestic violence in men; this study is comparable to Canada general social science survey on victimisation and national violence against women survey. By Canada general social science survey on victimization indicate that the most male victims were between 25 and 35 years of age where as in our study most male victims are under 36-40 years of age. A report by Kieran (2000) indicates that weak economic position of male victims to higher incidence of domestic violence where as in our study the government jobbed husbands have higher incidence of domestic violence.

According to national violence against women survey, 84.8\% men from white American Christian race experience violence among U.S population where as in our study $86.7 \%$ hindu have higher incidence of domestic violence in men. According to national violence against women survey $31.9 \%$ men in high school and equivalent education experience violence among U.S population where as in our study postgraduation men having $46.7 \%$ have higher incidence of domestic violence.

\section{Conclusion}

After the detailed analysis the study leads to the following conclusion:

Married men reported Domestic violence. Married men are subjected to more emotional violence by wife. The causes of domestic violence were in dominant behaviour of wife,
Attention seeking behaviour of wife, always right attitudes of wife, self-defence behaviour, always complain about physical illness and suspicious behaviour found in female.

\section{Recommendation}

On the basis of the finding of the study, it is recommended that:-

1) A similar study may be replicated in large scale.

2) Studies may be conducted to evaluate the effectiveness of the information booklet regarding the domestic violence against men.

3) A similar may be repeated on large sample covering all the population in the states.

4) A similar can be conducted on domestic violence in men in other population.

\section{References}

[1] Lowenstein, L. (2005). Domestic violence recent research (2004-2005) Part I: Incidence, types and causes. Police Journal, 78(2), 147-157.

[2] Ménard, K. S., Anderson, A. L., \& Godboldt, S. M (2009). Gender differences in intimate partner recidivism. Criminal Justice and Behavior, 36(1), 61-76.

[3] Barber, C. (2008). Domestic violence against men. Nursing Standard, 22(51), 35-39.

[4] Hines, D., Brown, J., \& Dunning, E. (2007). Characteristics of callers to the domestic abuse helpline for men. Journal of Family Violence, 22(2), 63-72.

[5] Kaur, P.,(2011) Crime, Gender and Society in India, Higher education of Social Science, 1(1), Pages 24-32,

[6] Linda, L. D. and Etienne G. K., (2002).World Report on Violence and Health, World health Organization Geneva,

[7] Kieran Mc keown \& philippa kidd, socio \& economic research consultants, Ireland

[8] Canadian center for justice statistics ,2000.

[9] U.S.popullaton:day, Jennifer cheeseman population projection of the united states by age, sex,race and Hispanic origin, 1998-2050. Current population reports; $p$ 25-104, Washington, D.C:U.S census bureau,1993. 